\title{
Functional analysis of PrkA - a putative serine protein kinase from Mesorhizobium alhagi CCNWXJ12-2 - in stress resistance
}

\author{
Xiaodong Liu, Yantao Luo, Zhefei Li and Gehong Wei
}

\begin{abstract}
Background: Serine/threonine protein kinases are highly conserved kinases with a wide distribution in microbes and with multiple functions. Mesorhizobium alhagi CCNWXJ12-2, a a-proteobacterium which could be able to form symbiosis with Alhagi sparsifolia in northwest of China, contains a putative PrkA-family serine protein kinase, PrkA. In our previous study, the expression of prkA was found to be downregulated in high-salt conditions. To elucidate the function of M. alhagi PrkA, a prkA deletion mutant was constructed and the phenotypes of the mutant were analyzed.

Results: The salt and alkaline tolerance and antioxidant capacity of the wild-type strain and the prkA deletion mutant was measured. Our results showed that the deletion mutant had higher salt and alkaline tolerance than the wild-type strain. The total cellular $\mathrm{Na}^{+}$content was measured and showed no significant difference between the wild-type strain and the mutant. The prkA deletion mutant also showed a higher $\mathrm{H}_{2} \mathrm{O}_{2}$ tolerance than the wild-type strain. Therefore the activities of antioxidant enzymes were measured. Catalase activity was similar in the wild-type and the deletion mutant, while the superoxide dismutase activity in the mutant was higher than that in the wildtype.

Conclusions: We firstly analyze the function of a serine protein kinase, PrkA, in M. alhagi. Our data indicate that PrkA could reduce the survival of $M$. alhagi under environmental stress and deletion of prkA dramatically improved the salt and alkaline tolerance and antioxidant capacity of $M$. alhagi.
\end{abstract}

Keywords: Serine protein kinase, Salt resistance, Antioxygenation, $\mathrm{Na}^{+}$concentration measurement

\section{Background}

Salinity and desiccation are major problems facing agriculture worldwide [1, 2]. Mesorhizobium alhagi CCNWXJ12-2 is a highly salt-tolerant and alkali-tolerant rhizobium which can form nodules with the desert plant Alhagi sparsifolia [3]. The nitrogen-fixing symbiosis formed between rhizobia and legumes can decrease the damage to plants caused by soil salinity; thus, there are an increasing number of studies on salt-tolerant rhizobia and their mechanism(s) of salt resistance $[4,5]$. To determine the mechanism of salt resistance in $M$. alhagi, a global transcriptome comparison of $M$. alhagi was conducted in salt-free (no added salt) and high-salt

\footnotetext{
* Correspondence: weigehong@nwsuaf.edu.cn

State Key Laboratory of Soil Erosion and Dryland Farming on the Loess

Plateau, College of Life Sciences, Northwest A \& F University, Yangling,
}

Shaanxi 712100, China conditions, and a downregulated putative serine kinase gene, prkA, was identified in high-salt [6].

PrkA is a highly conserved serine protein kinase with a wide distribution in bacteria and archaea [7]. The serine/threonine protein kinases play diverse roles in bacterial signal transduction and regulation by phosphorylating multiple substrates [8]. In the model bacterium Escherichia coli, the prkA homolog yeaG was regulated by leucine-responsive regulatory protein and may have a role in metabolic reprogramming to survive acidic and osmotic stress [9]. Recent reports showed that yea $G$ is also involved in adaptation to nutrient limitation $[10,11]$. However, subsequent research showed that a yea $G$ deletion mutant showed no significant difference in salt tolerance and $\mathrm{pH}$ adaptation compared with the wild-type strain [12]. 
In Mycobacterium tuberculosis, the deletion mutant of $p k n E$ (a gene encoding a serine/threonine protein kinase) showed defective growth in conditions of neutral $\mathrm{pH}$ and on exposure to lysozyme, but a higher tolerance to acidic stress, sodium dodecyl sulfate (SDS), and kanamycin [13]. Proteomic and phosphoproteomic analysis of the $p k n E$ mutant of $M$. tuberculosis showed that PknE was involved in metabolism, dormancy, and suppression of some sigma factors and other kinases, and thus could play an important role in adaptive responses to hostile environments [14].

In Bacillus subtilis, PrkA was proved to be an inner spore coat protein and involved in spore formation, which is controlled by sigma factors $[15,16]$. In Streptococcus mutans, the serine/threonine protein kinase annotated $p k n B$ was shown to play a significant role in biofilm formation, genetic competence, and acid resistance [17]. In Rhizobium etli, the expression of prkA was highly dependent on alarmones, guanosine, tetraphosphate, and guanosine pentaphosphate, but the $\Delta p r k A$ mutant of $R$. etli showed no clear difference compared with the wild-type under osmotic, oxidative and heat stresses [7].

In this study, we constructed a $\triangle p r k A$ (the prkA deletion mutant of $M$. alhagi) mutant and undertook a phenotypical analysis to understand the function of PrkA. Our results showed that the $\Delta$ prkA mutant grew better under high-salt $(0.4 \mathrm{M} \mathrm{NaCl})$ and alkaline $(\mathrm{pH} 9)$ conditions than the wild-type strain, and the survival rate of the mutant under oxidative stress was also higher than that of the wild-type. The total cellular $\mathrm{Na}^{+}$content in the mutant was almost the same as that in the wild-type in high-salt conditions. Although the catalase (CAT) activity was similar in the wild-type and $\triangle p r k A$ mutant, the superoxide dismutase (SOD) activity in $\triangle p r k A$ mutant was higher than that in the wild-type. These results indicate that prkA could reduce the ability of $M$. alhagi in stress adaptation.

\section{Results and discussions}

\section{Increased $\mathrm{NaCl}$ and alkali tolerance of mutant $\triangle p r k A$}

There is only one annotated PrkA family serine protein kinase in the genome of $M$. alhagi, denoted PrkA [18]. We have previously found that the expression of prkA was downregulated in high-salt conditions through RNA-Seq validated by RT-qPCR [6]. To determine the function of $M$. alhagi CCNWXJ12-2 prkA, we constructed a deletion mutant and its tolerance to $\mathrm{NaCl}$ and alkali were tested.

The mutant $\triangle p r k A$ had better salt and alkali resistance than the wild-type strain, while the complemented strain C $\Delta p r k A$ had similar salt and alkali resistance to the wild-type strain (Fig. 1). The expression of prkA in the complementation strain was confirmed using reverse transcription PCR (data not shown).

In Mycobacterium tuberculosis, the $p k n E$ deletion mutant showed higher tolerance to acidic stress, SDS, and kanamycin than the wild-type, which means $p k n E$ is involved in stress adaptation [13]. Although the protein sequence similarity of Mesorhizobium alhagi PrkA and Mycobacterium tuberculosis PknE is only $12.9 \%$, the function of $p k n E$ in $M$. tuberculosis was to some degree similar to that of prkA in $M$. alhagi in stress adaption. However, our results showed that wild-type $M$. alhagi had the same resistance to antibiotics (kanamycin, gentamicin, ampicillin, tetracycline, streptomycin, and rifampicin; $50 \mathrm{ug} / \mathrm{ml}$ for all), SDS (0.01\%), and acid ( $\mathrm{pH} \mathrm{6)}$ as did the mutant $\Delta p r k A$ (data not shown).

In $E$. coli, the deletion mutant of yeaG showed no difference in salt tolerance compared with the wildtype [12], although the similarity in protein sequence between E. coli YeaG and M. alhagi PrkA is relatively high (65.5\%). Despite the similar genomic background of prkA in $R$. etli and Mesorhizobium alhagi (data not shown) and the high similarity in protein sequences $(71.49 \%)$, the prkA deletion mutant of $R$. etli showed no phenotype changes compared with the wild-type strain [7], in contrast to $M$. alhagi in the present work.

The functions of these genes in the different bacteria are obviously different. These results show that serine protein kinases can have very different functions in different bacteria.

\section{Measurement of total cellular $\mathrm{Na}^{+}$content}

Bacteria can efflux the extra $\mathrm{Na}^{+}$from the cells by $\mathrm{Na}$ ${ }^{+} / \mathrm{H}^{+}$antiporters using energy of proton motive force [19]. We have previously found that the expression of a $\mathrm{Na}^{+} / \mathrm{H}^{+}$antiporter gene, nhaA, was upregulated in highsalt conditions [6]. Here we measured the total cellular $\mathrm{Na}^{+}$content of the wild-type, $\triangle p r k A$, and C $\Delta p r k A$ strains in salt-free and high-salt $(0.4 \mathrm{M} \mathrm{NaCl})$ conditions to find out whether PrkA influences the total cellular $\mathrm{Na}$ + content. However, our results showed no significant difference among these three strains $(p \geq 0.05)$ when grown in the same conditions (Fig. 2). The $\mathrm{Na}^{+}$content of the three strains grown on $0.4 \mathrm{M} \mathrm{NaCl} \mathrm{TY}$ agar plates was almost 20-fold higher than that in the controls grown on salt-free medium. The similar $\mathrm{Na}^{+}$content of the three strains implied that prkA does not depress the strain growth in high-salt conditions by adjusting the cellular $\mathrm{Na}^{+}$content. Therefore, we speculate that the mechanism of PrkA depressing the growth of Mesorhizobium alhagi under salt stress is complex, which involves many components of metabolism. 


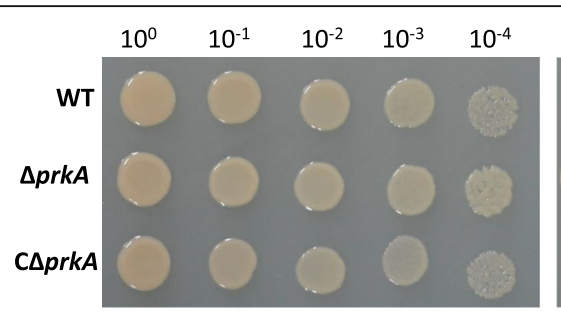

TY $0 \mathrm{M} \mathrm{NaCl} \mathrm{pH} 7$

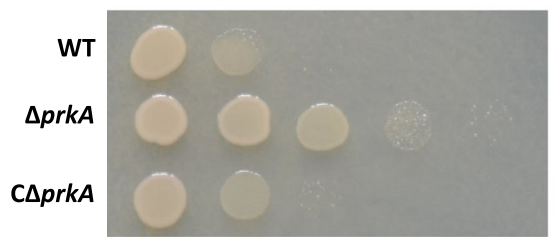

TY O M NaCl pH 9

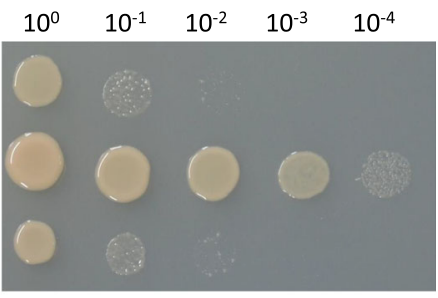

TY $0.4 \mathrm{M} \mathrm{NaCl} \mathrm{pH} 7$

Fig. 1 Sensitivity of the wild-type and mutant strains to $\mathrm{NaCl}$ and alkaline. Wild-type (WT), $\Delta$ prkA (prkA deletion mutant), and $C \Delta$ prkA (complement of $\Delta p r k A$ ) bacterial cells were grown to $\mathrm{OD}_{600} \approx 0.8$ in TY broth medium, adjusted to $\mathrm{OD}_{600} \approx 0.2$, and then serially diluted and spotted onto TY agar plates containing no additional $\mathrm{NaCl}$ or $0.4 \mathrm{M} \mathrm{NaCl}$ at neutral $\mathrm{pH}$, and TY agar plates at alkaline $\mathrm{pH}$ (pH 9). Ten-fold serial dilutions are shown. The plates with no additional $\mathrm{NaCl}$ were incubated at $28^{\circ} \mathrm{C}$ for 3 days, while the plates with $0.4 \mathrm{M} \mathrm{NaCl}$ and the plates at $\mathrm{pH} 9$ were incubated for 5 days at the same temperature

\section{Increased antioxidative capacity of mutant $\triangle p r k A$}

Stressful conditions such as heat, acid and high-salt concentrations, can lead to secondary oxidative stress in bacteria [20]. Previous study has shown the intracellular level of reactive oxygen species (ROS) was increased significantly when cells were stressed by high salinity [21, 22]. Because high salinity can trigger a high level of intracellular ROS, we tested the oxidative resistance of the $M$. alhagi prkA deletion mutant to identify any antioxidant function of PrkA. The survival rates of the wild-type, $\triangle p r k A$ and $\mathrm{C} \Delta p r k A$ strains treated with $10 \mathrm{mM} \mathrm{H}_{2} \mathrm{O}_{2}$ for 30 min showed a significant difference (Fig. 3); survival of $\triangle p r k A$ treated with $\mathrm{H}_{2} \mathrm{O}_{2}$ was significantly $(p \leq 0.05)$ higher than that of the wild-type and complemented strains. These results suggest that PrkA depresses the antioxidative capacity of $M$. alhagi.

Although $\mathrm{H}_{2} \mathrm{O}_{2}$ can be damaging for rhizobium, it appears that $\mathrm{H}_{2} \mathrm{O}_{2}$ is required for successful infection.

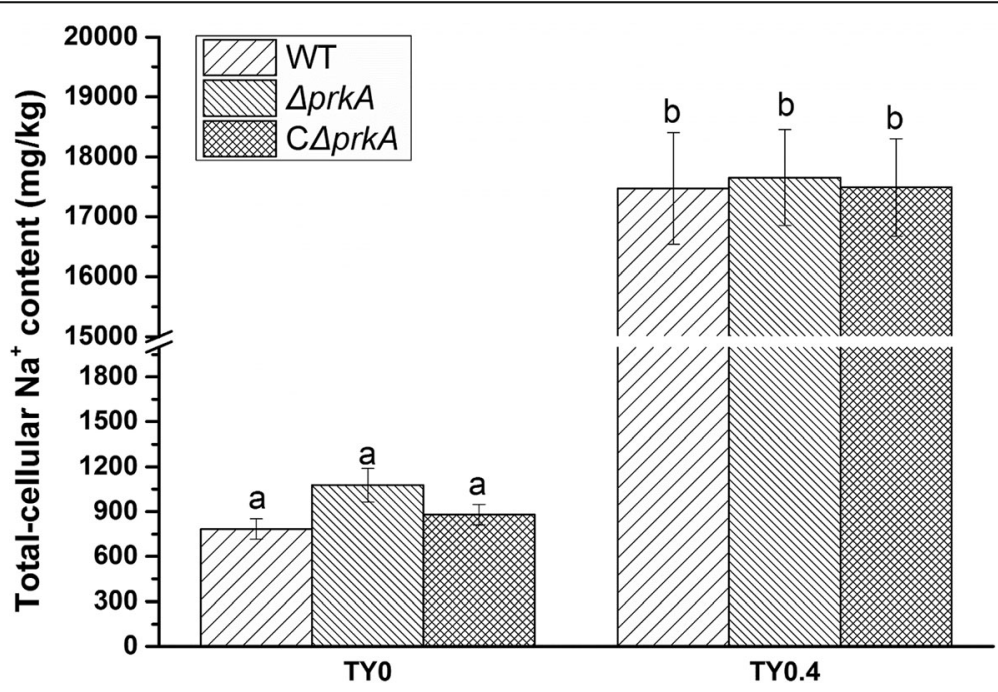

Fig. 2 Measurement of total cellular $\mathrm{Na}^{+}$concentration. Wild-type (WT), $\Delta p r k A$ (prkA deletion mutant), and $C \Delta p r k A$ (complement of $\Delta p r k A$ ) bacterial cells were grown to $\mathrm{OD}_{600} \approx 0.8$ in TY broth medium and then adjusted to $\mathrm{OD}_{600} \approx 0.2$. The diluted inocula were plated on TY agar plates with and without $0.4 \mathrm{M} \mathrm{NaCl}$ and inoculated at $28{ }^{\circ} \mathrm{C}$ for 5 days. Total cellular $\mathrm{Na}^{+}$concentrations were measured using an atomic absorption spectrophotometer. The results are shown as the means of three biological replicates and the error bars indicate standard deviations. The significance of differences is shown at the $P<0.05$ level ( $t$-test). Different lowercase letters mean significant difference between two columns 


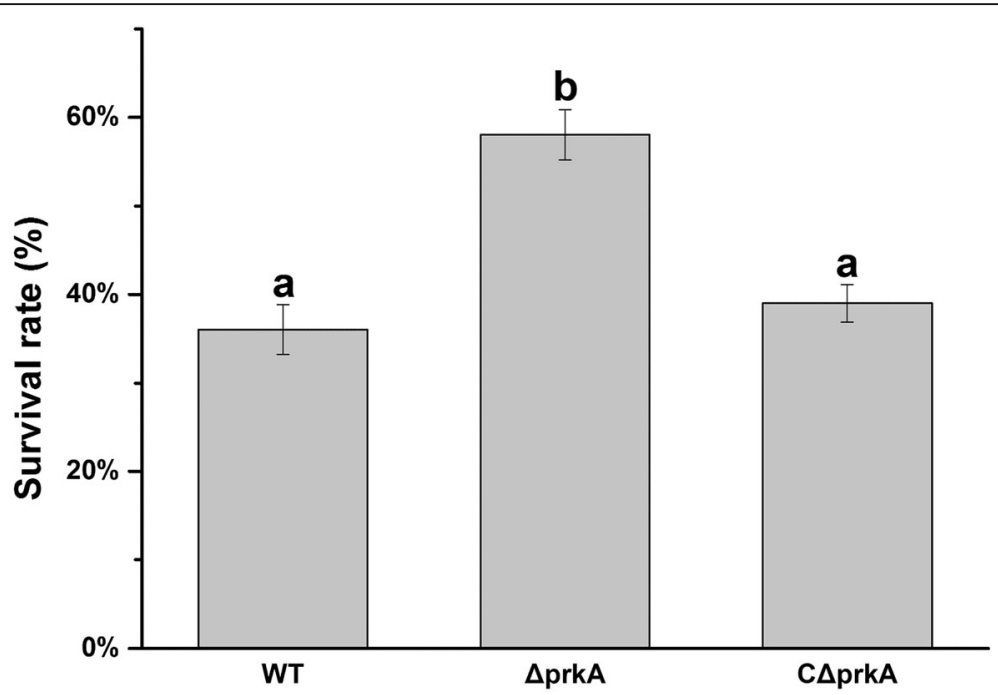

Fig. 3 Survival rate of M. alhagi after $\mathrm{H}_{2} \mathrm{O}_{2}$ treatment. Wild-type (WT), $\Delta p r k A$ (prkA deletion mutant), and $C \Delta p r k A$ (complement of $\Delta p r k A$ ) bacterial cells were grown to $\mathrm{OD}_{600} \approx 0.8$ in TY broth medium, adjusted to $\mathrm{OD}_{600} \approx 0.1$, and then treated with $10 \mathrm{mM} \mathrm{H}_{2} \mathrm{O}_{2}$ for 30 min or incubated without $\mathrm{H}_{2} \mathrm{O}_{2}$ in otherwise identical conditions as a control. The percentage survival rate of the three stains was calculated as follows: [(CFU per $\mathrm{ml}$ after treatment with $\left.\mathrm{H}_{2} \mathrm{O}_{2}\right) /\left(\right.$ CFU per $\mathrm{ml}$ before treatment with $\left.\left.\mathrm{H}_{2} \mathrm{O}_{2}\right)\right] \times 100$. Data shown are the means of three independent experiments and the error bars indicate standard deviations. The significance of differences is shown at the $P<0.05$ level (t-test). Different lowercase letters mean significant difference between two columns

The overexpression of the housekeeping catalase in Sinorhizobium meliloti $\mathrm{Rmkat}^{++}$results in a delay of symbiosis formation and has negative effects on the development of infection threads [23].

Unfortunately, the symbiosis formation of $M$. alhagi and Alhagi sparsifolia is very unstable. Great effort has been made to conduct the plant experiments, but the results are always unreliable and unauthentic (data not shown). Therefore, we can only hypothesize that PrkA has positive effects on symbiosis formation.

\section{Antioxidant enzyme activity determination}

Catalase (CAT), superoxide dismutase (SOD) and peroxidase (POD) are major antioxidases in bacteria, which can eliminate the intracellular ROS [24]. Therefore, we measured the CAT, SOD, and POD activities of $M$. alhagi in different conditions. Figure 4 shows the enzyme activity in the three strains (without treatment, $\mathrm{H}_{2} \mathrm{O}_{2}$ treated, or $0.4 \mathrm{M} \mathrm{NaCl}$ treated). The CAT and SOD activities could be detected in all strains in each condition, while the POD activity was not detectable.
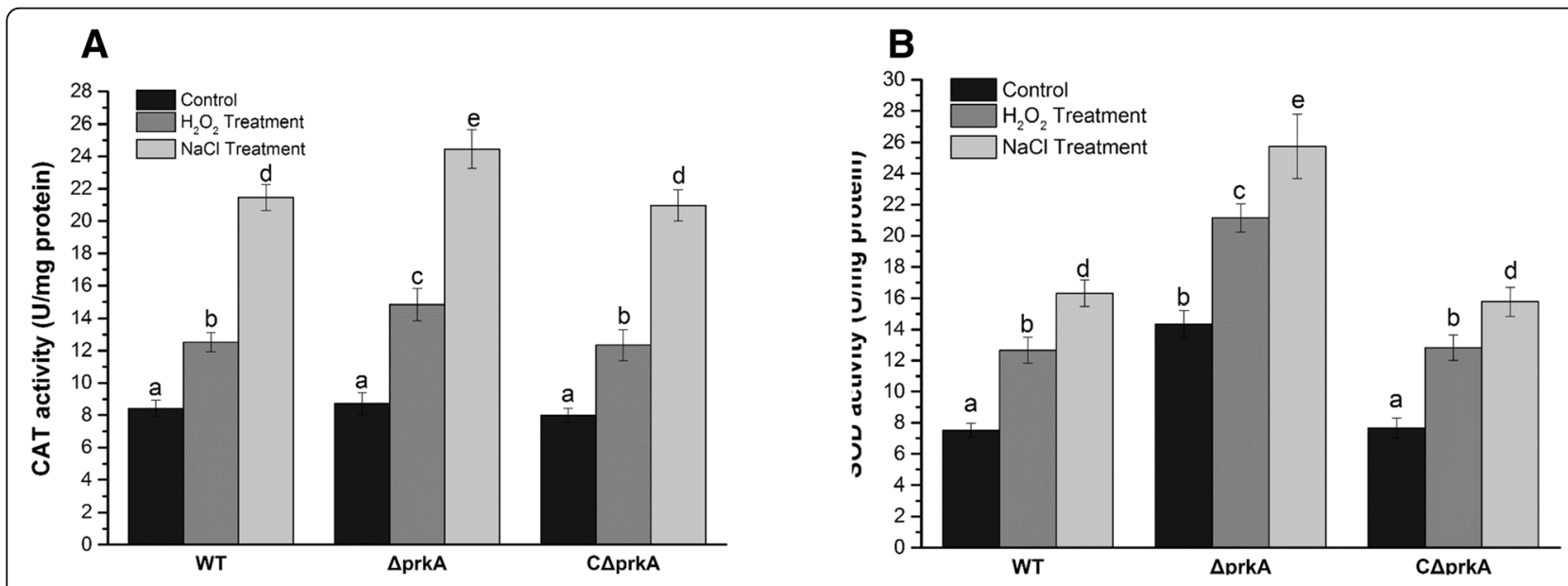

Fig. 4 Measurement of antioxidant enzyme activities. Measurement of catalase (CAT, (a)) and superoxide (SOD, (b)) activities in wild-type M. alhagi (WT), $\Delta p r k A$ (prkA deletion mutant), and $C \Delta p r k A$ (complement of $\Delta p r k A)$. Three independent biological experiments were conducted to measure the CAT and SOD activities. The error bars indicate standard deviations. The significance of differences is shown at the $P<0.05$ level (t-test). Different lowercase letters mean significant difference between two columns 
We checked the RNA-Seq data and found that the genes coding CATs and SODs are highly expressed in $M$. alhagi, while PODs are only expressed at a low level [6]; thus POD activity in cells may have been below the detection limit of the kit used in our experiments.

In control cells (normal conditions), the CAT activities of the three strains were almost the same, while the SOD activity of $\triangle p r k A$ was significantly higher $(p \leq 0.05)$ than that in the other two strains. Salt stress and $\mathrm{H}_{2} \mathrm{O}_{2}$ treatment triggered increased CAT and SOD activities in all three strains (Fig. 4). The CAT and SOD activities under high-salt stress were markedly higher than those in the $\mathrm{H}_{2} \mathrm{O}_{2}$ treatment group, which could also suggest that high-salt stresses trigger oxidative stress. The lower CAT and SOD activities in the $\mathrm{H}_{2} \mathrm{O}_{2}$ treatment group were possibly caused by the low $\mathrm{H}_{2} \mathrm{O}_{2}$ concentration or the short treatment time.

The CAT and SOD activities of $\triangle p r k A$ under salt stress and $\mathrm{H}_{2} \mathrm{O}_{2}$ treatment were extremely significantly higher $(p \leq 0.001)$ than those of the wild-type and C $\triangle$ prkA (Fig. 4). The increase in CAT activity units of $\triangle p r k A$ compared to the other two strains was much smaller than that in SOD activity units. Therefore, we hypothesize that PrkA influences the antioxidative capacity of $M$. alhagi mainly by affecting SOD activity. However, in favorable conditions (e.g., as in the control group), the high expression of SOD genes in $\triangle p r k A$ could waste energy. PrkA may play a role in control of SOD gene expression. The adjustment of SOD gene expression may need the high expression of $p r k A$ in saltfree conditions.

\section{Conclusions}

A prkA deletion mutant has been constructed to study the function of PrkA in $M$. alhagi. The data suggest that the ability to survive some abiotic stresses was increased by knocking out prkA. Moreover, we showed similarities and differences in the functions of PrkA and its homologs in $R$. etli and other bacteria. Our results suggest that it is possible to increase the salt and alkali tolerance of a bacterium by constructing specific mutants in genes highlighted by RNA-Seq data. To our knowledge, this is the first report to identify the function of PrkA in stress adaption of Mesorhizobium and to construct an increased salt-tolerant rhizobial mutant. Most curious and interesting was that the high expression of prkA made $M$. alhagi more vulnerable to high salinity. Because of the unstable symbiosis formation in plant tests, the role prkA plays in symbiosis formation is unclear and needs more efforts to be illuminated.

\section{Methods \\ Bacterial strains and growth conditions}

Table 1 lists bacterial strains and plasmids used in this study. The purified bacteria were typically grown in tryptone-yeast extract (TY) broth (5 g tryptone, $3 \mathrm{~g}$ yeast extract, and $0.7 \mathrm{~g} \mathrm{CaCl}_{2} \cdot 2 \mathrm{H}_{2} \mathrm{O}$ per liter) at $28{ }^{\circ} \mathrm{C}$ for $M$. alhagi and its mutants, or Luria-Bertani broth (10 g tryptone, $5 \mathrm{~g}$ yeast extract, and $10 \mathrm{~g} \mathrm{NaCl}$ per liter) at $37^{\circ} \mathrm{C}$ for Esherichia coli. SM agar plates $(10 \mathrm{~g}$ mannitol, $0.5 \mathrm{~g} \mathrm{~K}_{2} \mathrm{HPO}_{4}, 0.5 \mathrm{~g} \mathrm{KNO}_{3}, 0.2 \mathrm{~g} \mathrm{MgSO}_{4} \cdot 7 \mathrm{H}_{2} \mathrm{O}, 0.1 \mathrm{~g}$ $\mathrm{CaCl}_{2}, 0.1 \mathrm{~g} \mathrm{NaCl}$, and $15 \mathrm{~g}$ agar per liter) was used to isolate the mutants. All bacteria were incubated in aerobic conditions. Where necessary, antibiotics were

Table 1 Bacterial strains and plasmids used in this study

\begin{tabular}{|c|c|c|}
\hline Strain or plasmid & Description $^{a}$ & Source or reference \\
\hline \multicolumn{3}{|l|}{ Escherichia coli } \\
\hline $\mathrm{DH} 5 \mathrm{a}$ & 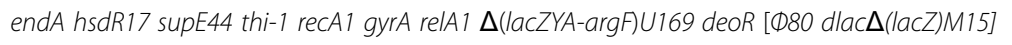 & {$[27]$} \\
\hline S17-1入pir & $\operatorname{Tp}^{r}$ Str recA thi pro hsdR hsdM+ RP4::2-Tc::Mu::Km Tn7 $\lambda$ pir lysogen & {$[28]$} \\
\hline DH-PrkA & DH5a carrying pK18prkA & This study \\
\hline DH-CPrkA & DH5a carrying pBLprkA & This study \\
\hline \multicolumn{3}{|c|}{ Mesorhizobium alhagi } \\
\hline $\mathrm{XJ12-2}$ & Wild-type & [18] \\
\hline$\triangle p r k A$ & XJ12-2 $\Delta p r k A$ & This study \\
\hline$C \Delta p r k A$ & $\triangle p r k A$ carrying pBLprkA & This study \\
\hline \multicolumn{3}{|l|}{ Plasmids } \\
\hline pK18mobsacB & Suicide vector derived from plasmid pK18; $\mathrm{Mob}^{+}$sacB $\mathrm{Km}^{\mathrm{r}}$ & {$[25]$} \\
\hline pBBR1MCS-5 & Broad-host-range cloning vector; $\mathrm{Gm}^{r}$ & [29] \\
\hline pK18prkA & pK18mobsacB::prkA & This study \\
\hline pBLprkA & $\mathrm{pBL}$ carrying prkA & This study \\
\hline
\end{tabular}

${ }^{\mathrm{a}} \mathrm{Km}^{\mathrm{r}}$, kanamycin resistance; $\mathrm{Gm}^{\mathrm{r}}$, gentamicin resistance 
added as the following concentrations: kanamycin, $100 \mu \mathrm{g} / \mathrm{ml}$; gentamicin $50 \mu \mathrm{g} / \mathrm{ml}$.

\section{Plasmid construction}

The primers used to construct the prkA deletion mutant and the complementation strain are listed in Table 2. Primers PrkA-US and PrkA-UA were used to amplify a 208-bp upstream fragment of prkA with an EcoRI restriction enzyme site at the $5^{\prime}$ end and a BamHI site at the $3^{\prime}$ end. Primers PrkA-DS and PrkA-DA were used to amplify a 444-bp downstream fragment of prkA containing a BamHI restriction enzyme site at the $5^{\prime}$ end and an XbaI site at the $3^{\prime}$ end. The two fragments were then digested with the relevant restriction enzymes using standard protocols. The two digested fragments were then cloned into plasmid pk18mobsacB digested with the same enzymes to generate plasmid pK18prkA, which was verified by sequencing [25].

To construct the plasmid for prkA-complementation, a DNA fragment containing full-length $p r k A$ and a putative promoter of prkA (500 bp upstream of prkA) was amplified from genome DNA of $M$. alhagi using primers CPA and $\mathrm{CPB}$. The PCR product was then purified using a Universal DNA Purification Kit (Tiangen, China). The purified PCR product was cloned into plasmid pBBR1MCS-5 digested with SmaI, using the ClonExpress MultiS One Step Cloning Kit (Vazyme Biotech, China), to generate the complementation plasmid pBLprkA, which was verified by sequencing.

\section{Mutant and complement construction}

To construct the prkA deletion mutant, we first trans-

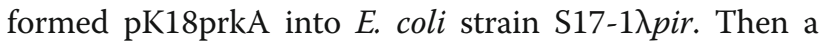
biparental mating procedure was used, as described previously [26], to transform pK18prkA from E. coli S17$1 \lambda$ pir into $M$. alhagi CCNWXJ12-2. Briefly, cultures of E. coli S17-1 $\lambda$ pir $\left(\mathrm{OD}_{600}\right.$ [optical density at $600 \mathrm{~nm}$ ] $0.6)$ and $M$. alhagi CCNWXJ12-2 $\left(\mathrm{OD}_{600} \approx 0.8\right)$ were mixed together in the ratio $1: 2(\mathrm{v} / \mathrm{v})$ and cultured on a TY agar plate for 3 days. Single exchange (plasmid

Table 2 Primers used for mutant and complement strain construction

\begin{tabular}{|c|c|}
\hline Primer & Sequence $^{a}\left(5^{\prime}-3^{\prime}\right)$ \\
\hline PrkA-US & CGGAATTCTCCTTCGTTCGCGGA \\
\hline PrkA-UA & CGGGATCCGACCTCGTTGCCGA \\
\hline PrkA-DS & CGGGATCCGCCTTCCCATATCAG \\
\hline PrkA-DA & GCTCTAGACACTTCCTCCGTGTCGT \\
\hline CPA & $\begin{array}{l}\text { ATGAAGTCGCTTAATCCCCCGGGC } \\
\text { ATCGGGTCCGGCGCCGGATCGGG }\end{array}$ \\
\hline CPB & $\begin{array}{l}\text { TAACAAAATATTAACGCCCCGGGT } \\
\text { CAGCCCGCCTTGTTGACGCGCATG }\end{array}$ \\
\hline
\end{tabular}

${ }^{\mathrm{a}}$ Restriction enzyme sites are underlined
pK18prkA integrated into genome DNA of $M$. alhagi) cells of $M$. alhagi were selected using SM agar plates containing kanamycin. Double exchange mutants (prkA deletion mutant) were then isolated using TY agar plates containing sucrose $(5 \mathrm{~g} / 100 \mathrm{ml})$. Both of single-exchange and double-exchange mutants were verified by colony PCR and sequencing.

For genetic complementation, pBLprkA was trans-

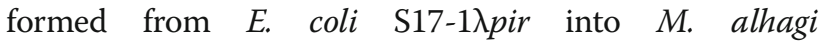
CCNWXJ12-2 by biparental mating. SM agar plates containing gentamicin were used to isolate the complementation mutant, and colony PCR and sequencing were used to verify the mutant strain.

\section{Salt and alkali resistance assays}

Wild-type $M$. alhagi, $\triangle p r k A$, and $C \triangle p r k A$ were first grown in $20 \mathrm{ml}$ TY broth to $\mathrm{OD}_{600} \approx 0.8$. Then suspensions $(20 \mu \mathrm{l})$ of the three cultures were added to $20 \mathrm{ml}$ $\mathrm{TY}$ broth and grown to $\mathrm{OD}_{600} \approx 0.8$. The inocula were adjusted to $\mathrm{OD}_{600} \approx 0.2$ with sterile water and then serially diluted to 10 -fold. Then $5 \mu \mathrm{l}$ of each diluted inoculum were respectively spotted onto TY agar plates at pH 7 containing no $\mathrm{NaCl}$ (control) or $0.4 \mathrm{M} \mathrm{NaCl}$ (salt treatment), or $\mathrm{TY}$ agar plates at $\mathrm{pH} 9$ containing no $\mathrm{NaCl}$ (alkaline treatment). The $\mathrm{pH}$ of TY agar medium was adjusted using $\mathrm{NaOH}$ solution $\left(\begin{array}{ll}1 & M\end{array}\right)$ before sterilization.

\section{Measurement of total cellular $\mathrm{Na}^{+}$content}

Inocula were prepared as described in the section on the salt and alkali resistance assay. Five hundred microliters of each inoculum $\left(\mathrm{OD}_{600} \approx 0.2\right)$ were plated on $\mathrm{TY}$ agar plates with and without $0.4 \mathrm{M} \mathrm{NaCl}$ and inoculated at $28{ }^{\circ} \mathrm{C}$ for 7 days. The bacteria were collected in $1.5-\mathrm{ml}$ sterile tubes and dried using an air dryer at $50{ }^{\circ} \mathrm{C}$ for $12 \mathrm{~h}$. The total cellular $\mathrm{Na}^{+}$content was measured using an atomic absorption spectrophotometer (Hitachi, Tokyo, Japan).

\section{Sensitivity assay of $\mathrm{H}_{2} \mathrm{O}_{2}$}

Inocula $\left(\mathrm{OD}_{600} \approx 0.1\right)$ were treated with or without $10 \mathrm{mM} \mathrm{H}_{2} \mathrm{O}_{2}$ for $30 \mathrm{~min}$, then serially diluted and plated on TY agar plates. The colonies were counted after 10 days of growth at $28{ }^{\circ} \mathrm{C}$. The percentage survival rate of the three stains was calculated as follows: [(CFU per $\mathrm{ml}$ after treatment with $\left.\mathrm{H}_{2} \mathrm{O}_{2}\right) /(\mathrm{CFU}$ per $\mathrm{ml}$ before treatment with $\mathrm{H}_{2} \mathrm{O}_{2}$ )] $\times 100$.

\section{Antioxidant enzyme activity assays}

Wild-type $M$. alhagi, $\triangle p r k A$ and $C \Delta p r k A$ were grown in TY broth medium to $\mathrm{OD}_{600} \approx 0.8$. Each strain $(20 \mu \mathrm{l}$ suspension) was added to two bottles of $20 \mathrm{ml}$ TY broth medium without additional $\mathrm{NaCl}$ and one bottle of $20 \mathrm{ml}$ TY broth medium containing $0.4 \mathrm{M} \mathrm{NaCl}$. Then 
the bacteria were grown to $\mathrm{OD}_{600} \approx 0.8$. One bottle of TY broth medium without $\mathrm{NaCl}$ was set as the control group and the other was treated with $0.1 \mathrm{mM} \mathrm{H}_{2} \mathrm{O}_{2}$ for $30 \mathrm{~min}\left(\mathrm{H}_{2} \mathrm{O}_{2}\right.$ treatment). Then all groups for the three strains were collected in $50-\mathrm{ml}$ tubes by centrifugation at $8000 \mathrm{~g}$ for $5 \mathrm{~min}$. The cells were lysed by ultrasonication. The enzyme activities of CAT, SOD and POD were determined using a CAT Assay Kit, a SOD Assay Kit, and a POD Assay Kit (Suzhou Comin Biotechnology, China), respectively, according to the manufacturer's protocols. Total soluble protein concentration was measured using a BCA Protein Assay Kit (CWBIO, China).

\section{Statistical analysis}

Statistical differences between the control and treatment groups of different strains were assessed by $t$-test using SPSS software version 15 (SPSS Inc., Chicago, IL, USA). Differences were considered to be significant at a probability level of $\mathrm{P}<0.05$.

\section{Abbreviations}

CAT: Catalase; CFU: Colony forming units; C $\triangle$ prkA: The complemented strain of $\triangle p r k A ;$ POD: Peroxidase; SDS: Sodium dodecyl sulfate; SOD: Superoxide dismutase; $\Delta p r k A$ : The prkA deletion mutant of Mesorhizobium alhagi CCNWXJ12-2

\section{Acknowledgements}

The authors would like to thank the National Science Foundation of China and the Fundamental Research Funds for the Central Universities for financial support.

\section{Funding}

This work was supported by grants from the National Science Foundation of China (31270012) and the Fundamental Research Funds for the Central Universities (2014YQ004)

\section{Availability of data and materials}

The datasets supporting the conclusions of this article are included within the article. The DNA sequence of the M. alhagi CCNWXJ12-2 prkA sequence is available under the accession No AHAM01000144.1. The M. alhagi CCNWXJ12-2 and the mutant strains can be obtained from the lab of Gehong Wei upon request.

\section{Authors' contributions}

$\mathrm{XL}, \mathrm{YL}$ and $\mathrm{GH}$ make conception and design of this work. $\mathrm{XL}$ and $\mathrm{YL}$ conduct the laboratory work. XL and ZL carry out the data analysis and manuscript writing. All authors read and approved the final manuscript.

\section{Competing interests}

The authors declare that they have no competing interests.

\section{Consent for publication}

Not applicable.

\section{Ethics approval and consent to participate}

Not applicable.

Received: 27 May 2016 Accepted: 24 September 2016 Published online: 29 September 2016

\section{References}

1. Vriezen JAC, de Bruijn FJ, Nusslein K. Responses of rhizobia to desiccation in relation to osmotic stress, oxygen, and temperature. Appl Environ Microb. 2007;73(11):3451-9.
2. Zahran HH. Rhizobium-legume symbiosis and nitrogen fixation under severe conditions and in an arid climate. Microbiol Mol Biol R. 1999;63(4):968-89.

3. Chen WM, Zhu WF, Bontemps C, Young JPW, Wei GH. Mesorhizobium alhagi sp nov., isolated from wild Alhagi sparsifolia in north-western China. Int J Syst Evol Micr. 2010;60:958-62.

4. Oufdou K, Benidire L, Lyubenova L, Daoui K, Fatemi ZE, Schroder P. Enzymes of the glutathione-ascorbate cycle in leaves and roots of rhizobiainoculated faba bean plants (Vicia faba L.) under salinity stress. Eur J Soil Biol. 2014;60:98-103.

5. Zaman-Allah M, Sifi B, Issoufou M, El Aouni MH. Salt tolerance of a common bean (Phaseolus vulgaris L.) cultivar as affected by rhizobia. Symbiosis. 2005:40(1):17-22.

6. Liu XD, Luo YT, Mohamed OA, Liu DY, Wei GH. Global transcriptome analysis of Mesorhizobium alhagi CCNWXJ12-2 under salt stress. Bmc Microbiol. 2014;14:1.

7. Vercruysse M, Fauvart M, Jans A, Beullens S, Braeken K, Cloots L, Engelen K, Marchal K, Michiels J. Stress response regulators identified through genomewide transcriptome analysis of the (p) ppGpp-dependent response in Rhizobium etli. Genome Biol. 2011;12(2):R17.

8. Cousin C, Derouiche A, Shi L, Pagot Y, Poncet S, Mijakovic I. Protein-serine/ threonine/tyrosine kinases in bacterial signaling and regulation. Fems Microbiol Lett. 2013;346(1):11-9.

9. Tani TH, Khodursky A, Blumenthal RM, Brown PO, Matthews RG. Adaptation to famine: a family of stationary-phase genes revealed by microarray analysis. Proc Natl Acad Sci U S A. 2002;99(21):13471-6.

10. Figueira R, Brown DR, Ferreira D, Eldridge MJ, Burchell L, Pan Z, Helaine $S$, Wigneshweraraj S. Adaptation to sustained nitrogen starvation by Escherichia coli requires the eukaryote-like serine/threonine kinase YeaG. Sci Rep. 2015;5:17524.

11. Brown DR, Barton G, Pan Z, Buck M, Wigneshweraraj S. Nitrogen stress response and stringent response are coupled in Escherichia coli. Nat Commun. 2014:5:4115

12. Tagourti J, Gautier V, Beaujouan JC, Gauchy C, Landoulsi A, Richarme G. Phosphorylation of a $65 \mathrm{kDa}$ cytoplasmic protein by the Escherichia coli YeaG kinase. Ann Microbiol. 2011;61(3):499-503.

13. Kumar D, Palaniyandi K, Challu VK, Kumar P, Narayanan S. PknE, a serine/ threonine protein kinase from Mycobacterium tuberculosis has a role in adaptive responses. Arch Microbiol. 2013;195(1):75-80.

14. Parandhaman DK, Sharma P, Bisht D, Narayanan S. Proteome and phosphoproteome analysis of the serine/threonine protein kinase E mutant of Mycobacterium tuberculosis. Life Sci. 2014;109(2):116-26.

15. Eichenberger P, Jensen ST, Conlon EM, van Ooij C, Silvaggi J, GonzalezPastor JE, Fujita M, Ben-Yehuda S, Stragier P, Liu JS, et al. The sigmaE regulon and the identification of additional sporulation genes in bacillus subtilis. J Mol Biol. 2003;327(5):945-72.

16. Yan JY, Zou W, Fang J, Huang XW, Gao F, He ZY, Zhang KQ, Zhao NH Eukaryote-like Ser/Thr protein kinase PrkA modulates sporulation via regulating the transcriptional factor sigma $(\mathrm{k})$ in bacillus subtilis. Front Microbiol. 2015;6:382.

17. Hussain H, Branny P, Allan E. A eukaryotic-type serine/threonine protein kinase is required for biofilm formation, genetic competence, and acid resistance in Streptococcus mutans. J Bacteriol. 2006;188(4):1628-32.

18. Zhou ML, Chen WM, Chen HY, Wei GH. Draft genome sequence of Mesorhizobium alhagi CCNWXJ12-2(Tau), a novel salt-resistant species isolated from the desert of Northwestern China. J Bacteriol. 2012;194(5):1261-2.

19. Morino M, Suzuki T, Ito M, Krulwich TA. Purification and functional reconstitution of a seven-subunit mrp-type nat/h + antiporter. J Bacteriol. 2014;196(1):28-35.

20. Mols M, Abee T. Primary and secondary oxidative stress in bacillus. Environ Microbiol. 2011;13(6):1387-94.

21. Koh MJ, Lee HS, Rhee JE, Choi SH. Evidence that vibrio vulnificus AhpC2 is essential for survival under high salinity by modulating intracellular level of ROS. J Microbiol. 2010;48(1):129-33.

22. Calderon-Torres M, Castro DE, Montero P, Pena A. DhARO4 induction and tyrosine nitration in response to reactive radicals generated by salt stress in Debaryomyces hansenii. Yeast. 2011;28(10):733-46.

23. Jamet A, Mandon K, Puppo A, Herouart D. H2O2 is required for optimal establishment of the Medicago sativa/Sinorhizobium meliloti symbiosis. J Bacteriol. 2007;189(23):8741-5. 
24. Harrison A, Bakaletz LO, Munson Jr RS. Haemophilus influenzae and oxidative stress. Front Cell Infect Microbiol. 2012;2:40,

25. Schafer A, Tauch A, Jager W, Kalinowski J, Thierbach G, Puhler A. Small mobilizable multi-purpose cloning vectors derived from the Escherichia coli plasmids pK18 and pK19: selection of defined deletions in the chromosome of Corynebacterium glutamicum. Gene. 1994;145(1):69-73.

26. Dhooghe I, Michiels J, Vlassak K, Verreth C, Waelkens F, Vanderleyden J. Structural and Functional-Analysis of the Fixlj Genes of RhizobiumLeguminosarum Biovar Phaseoli Cnpaf512. Mol Gen Genet. 1995;249(1):117-26.

27. Hanahan D. Studies on transformation of Escherichia coli with plasmids. J Mol Biol. 1983;166(4):557-80.

28. Miller VL, Falkow S. Evidence for two genetic loci in Yersinia enterocolitica that can promote invasion of epithelial cells. Infect Immun. 1988;56(5):1242-8.

29. Kovach ME, Elzer PH, Hill DS, Robertson GT, Farris MA, Roop RM, Peterson KM. 4 New derivatives of the broad-host-range cloning vector Pbbr1mcs, carrying different antibiotic-resistance cassettes. Gene. 1995;166(1):175-6.

Submit your next manuscript to BioMed Central and we will help you at every step:

- We accept pre-submission inquiries

- Our selector tool helps you to find the most relevant journal

- We provide round the clock customer support

- Convenient online submission

- Thorough peer review

- Inclusion in PubMed and all major indexing services

- Maximum visibility for your research

Submit your manuscript at www.biomedcentral.com/submit
Biomed Central 